\title{
Electrochemical immunosensor for multiplexed detection of food-borne pathogens using nanocrystal bioconjugates and MWCNT screen-printed electrode
}

\author{
Subramanian Viswanathan, Chinnakkaruppanan Rani, Ja-an Annie Ho
}

\begin{abstract}
A B S T R A C T
Bacterial food poisoning is an ever-present threat that can be prevented with proper care and handling of food products. A disposable electrochemical immunosensor for the simultaneous measurements of common food pathogenic bacteria namely Escherichia coli 0157:H7 (E. coli), campylobacter and salmonella were developed. The immunosensor was fabricated by immobilizing the mixture of anti-E. coli, anticampylobacter and anti-salmonella antibodies with a ratio of $1: 1: 1$ on the surface of the multiwall carbon nanotube-polyallylamine modified screen printed electrode (MWCNT-PAH/SPE). Bacteria suspension became attached to the immobilized antibodies when the immunosensor was incubated in liquid samples. The sandwich immunoassay was performed with three antibodies conjugated with specific nanocrystal ( $\alpha$-E. coli-CdS, $\alpha$-campylobacter-PbS and $\alpha$-salmonella-CuS) which has releasable metal ions for electrochemical measurements. The square wave anodic stripping voltammetry (SWASV) was employed to measure released metal ions from bound antibody nanocrystal conjugates. The calibration curves for three selected bacteria were found in the range of $1 \times 10^{3}-5 \times 10^{5} \mathrm{cells} \mathrm{mL}^{-1}$ with the limit of detection (LOD) 400 cells $\mathrm{mL}^{-1}$ for salmonella, 400 cells $\mathrm{mL}^{-1}$ for campylobacter and 800 cells $\mathrm{mL}^{-1}$ for E. coli. The precision and sensitivity of this method show the feasibility of multiplexed determination of bacteria in milk samples.
\end{abstract}

Keywords:

Immunosensors

Carbon nanotube

Escherichia coli

Campylobacter

Salmonella

Screen printed electrode

\section{Introduction}

Outbreaks of pathogenic food or water-borne diseases remain a major challenge to public health providers, claiming millions of lives annually, worldwide [1,2]. Characterization of such microorganisms is critical for the diagnosis and subsequent treatment of infectious diseases, as well as for the detection of biohazards in the environment [3,4]. Pathogens such as salmonella, Escherichia coli 0157:H7 (E. coli), Campylobacter jejuni, and Vibrio cholera are more likely to contaminate fresh produce through vehicles such as raw or improperly composted manure, irrigation water containing untreated sewage, or contaminated wash water [5]. Every year in the United States there are millions of people who have been affected by water and food borne illness caused by Campylobacter spp., Salmonella, and E. coli [6-8]. Although these pathogens usually cause mild to moderate self-limiting gastroenteritis, invasive diseases and complications may occur, resulting in more severe cases [8]. For example, Campylobacter has been identified as the predominant cause of Guillain-Barré syndrome and reactive arthritis [9]. Systemic salmonellosis infections can be lifethreatening [10], and Shiga toxin-producing E. coli, particularly E. coli, can cause a bloody diarrhea and hemolytic uremic syndrome. Campylobacter, Salmonella, and E. coli colonize the gastrointestinal tracts of a wide range of wild and domestic animals, especially animals raised for human consumption [11]. Food contamination with these pathogenic bacteria can occur at multiple steps along the food chain, including production, processing, distribution, retail marketing, and handling or preparation. Numerous epidemiological reports have implicated foods of animal origin as the major vehicles associated with illnesses caused by food-borne pathogens $[12,13]$. Contaminated raw or undercooked vegetables [14], poultry, dairy products, red meat, etc., are particularly important in transmitting these food-borne pathogens. Since food regulatory agencies have established strict control programs in order to avoid food pathogens entering the food supply, official laboratories should be able to process a high number of samples rapidly [15]. There is an urgent need for rapid assays for screening food and environmental samples for pathogens. Many methods have been developed in an effort to replace traditional techniques that usually take two to three days for biochemical and serological characterization [16]. Electrochemical methods [17], surface plasmon resonance [18], polymerase chain reaction [19], have been developed and studied for the 
determination of pathogens. However, most of the available methods of food quality control techniques are time consuming, expensive and labour intensive.

Electrochemical biosensors offer several advantages, compared to other detection approaches, including the ability to analyze complex environmental samples, high sensitivity, a low power requirement, and compatible with portable devices [20]. Recently, electrochemical immunosensors based on screen-printed electrodes (SPE) challenge the conventional electrochemical biosensors for fabrication, disposability and portability [21-23]. The remarkable conductivity of carbon nanotubes (CNT) and their interesting electrochemical properties have led to an intensive research activity in the field of CNT based electrochemical sensors in recent years. The coupling of functional polymers with carbon nanotubes is an increasing importance due to its simplicity of construction and its ability to incorporate conducting materials into porous polymers in order to form electrochemical biosensors. Carbon nanotube composites with nafion [24], teflon, epoxy, chitosan, polypyrrole and poly(ethylenedioxythiophene) [25] were reported in order to improve robustness of CNT electrodes and to facilitate immobilization of biocomponents. Nanoparticles can be used in a variety of bioanalytical formats with electrochemical detection. When nanoparticles are used as labels, an electrochemical signal emanating from the particles is quantified [26]. This paper describes a simple approach toward the determination of pathogenic bacteria using an immunosensor based on immunosensitized multiwall carbon nanotube-polyallylamine screen printed electrode ( $\alpha$-MWCNT-PAH/SPE) and nanocrystal antibody conjugates.

\section{Experimental and methods}

\subsection{Reagents}

Escherichia coli 0157:H7 (E. coli) and its anti-E. coli monoclonal antibody ( $\alpha$-E. coli) were purchased from Sigma (USA). Campylobacter, Salmonella and its monoclonal antibodies were purchased from Kirkegaard \& Perry Laboratories Inc. (USA). SPE were purchased for Zensor R\&D (Taiwan). All other analytical reagents, proteins and solvents were purchased from Sigma and were used without further purification.

\subsection{Instruments}

SEM images of electrode surface were obtained using HITACHI S-4700 scanning electron microscope (Hitachi, Japan). Infrared spectra were recorded using Perkin Elmer RXI FT-IR spectrometer (Norwalk, CT, USA) and anhydrous potassium bromide discs. Square-wave voltammetric stripping measurements were performed with $\mathrm{CHI}$ 660B (CH Instruments, Austin, TX). $100 \mu \mathrm{L}$ capacity polypropylene hollow cylinder $(6 \mathrm{~mm}$ inner diameter $\times 6 \mathrm{~mm}$ height) attached on SPE (carbon disk working electrode, 5 -mm diameter) was used as electrochemical cell with $\mathrm{Ag} / \mathrm{AgCl}$ reference electrode, and a platinum wire counter electrode.

\subsection{Preparation of the nanocrystals bioconjugates}

NC and bioconjugates were synthesized using previously reported procedure [26]. Both protocols are briefly described below. For NC synthesis, sodium bis(2-ethylhexyl) sulfosuccinate (AOT) $(14.0 \mathrm{~g}$ ) was first dissolved in a mixture of n-heptane:water (200 mL:4 mL). The resulting solution was separated into two subvolumes of $120 \mathrm{~mL}$ and $80 \mathrm{~mL}$. A $0.48 \mathrm{~mL}$ aliquot of a $1 \mathrm{M} \mathrm{Cu}\left(\mathrm{NO}_{3}\right)_{2}$ or $\mathrm{Pb}\left(\mathrm{NO}_{3}\right)_{2}$ or $\mathrm{Cd}\left(\mathrm{NO}_{3}\right)_{2}$ solution was added to the $120 \mathrm{~mL}$ subvolume, while a $0.32 \mathrm{~mL}$ of the $1 \mathrm{M} \mathrm{Na}_{2} \mathrm{~S}$ solution was added to the $80 \mathrm{~mL}$ sub-volume. The sub-volumes were stirred for $1 \mathrm{~h}$, then mixed and stirred for an additional hour under nitrogen. The quantum dots were capped by adding cysteamine $(0.34 \mathrm{~mL}, 0.32 \mathrm{M})$ and sodium 2-mercaptoethane sulfonate $(0.66 \mathrm{~mL}, 0.32 \mathrm{M})$ and mixing under nitrogen for $24 \mathrm{~h}$. The resulting NCs were obtained by evaporating the heptane in vacuum and washing with pyridine, hexane and methanol.

Antibody sensitized NCs were prepared according to the procedure of Thompson and co-workers [27]. The NC were functionalized with carboxyl groups by suspending $6.0 \mathrm{mg}$ of the NC in $600 \mu \mathrm{L}$ of 11-mercaptoundecanoic acid ( $0.1 \mathrm{M}$ in $4: 1, \mathrm{v} / \mathrm{v}$ ethanol:water), and mixing for $30 \mathrm{~min}$. The excess thiol was removed during a 5 min centrifugation at $3000 \mathrm{rpm}$, followed by removal of the supernatant, and dispersion in $120 \mu \mathrm{L}$ of phosphate buffer solution, PBS $(20 \mathrm{mM}, \mathrm{pH}=8.6)$. A $10 \mu \mathrm{L}$ of the above suspension were diluted to $100 \mu \mathrm{L}$ with PBS. This was followed by additions of $1 \mathrm{mg} \mathrm{N}$-(3-dimethylamminopropyl)-N'-ethylcarbodiimide hydrochloride (EDC) and $1 \mathrm{mg} \mathrm{N}$-hydroxysulfosuccinimide sodium salt (NHS). The mixture was stirred for $30 \mathrm{~min}$, centrifuged for $1 \mathrm{~min}$ at $3000 \mathrm{rpm}$ to remove the supernatant, and was then dispersed in $250 \mu \mathrm{L}$ PBS. This was followed by the adding the anti-Salmonella, anti-Campylobacter, anti-E. coli antibodies $(15 \mu \mathrm{L}$, 100 ppm in water) with CuS, PbS and CdS respectively and mixed for $1 \mathrm{~h}$. The NC-antibody conjugates were collected for further use by centrifugation, removal of the supernatant, and resuspended in $1200 \mu \mathrm{L}$ of Tris- $\mathrm{HCl}$ buffer ( $50 \mathrm{mM}$ Tris- $\mathrm{HCl}, 100 \mathrm{mM} \mathrm{NaCl}, 5 \mathrm{mM}$ $\mathrm{KCl} ; \mathrm{pH} 7.4)$.

\subsection{Functionalization of MWCNT}

A $50 \mathrm{~mL}$ flask loaded with $500 \mathrm{mg}$ of crude MWCNTs and $10 \mathrm{~mL}$ of $60 \% \mathrm{HNO}_{3}$ aqueous solution was sonicated in a bath for $30 \mathrm{~min}$. The mixture was then stirred for $24 \mathrm{~h}$ under reflux. After cooling to room temperature, it was diluted with $40 \mathrm{~mL}$ of deionized water and then vacuum filtered through a $0.2 \mu \mathrm{m}$ polycarbonate membrane. The solid was washed with deionized water until the $\mathrm{pH}$ value of the filtrate was 7 . The filtered solid was then dried under vacuum for $24 \mathrm{~h}$ at $40^{\circ} \mathrm{C}$ to give about $\sim 300 \mathrm{mg}$ of carboxylic acidfunctionalized MWCNT [28].

\subsection{Fabrication of the immunosensors}

The modification of the graphite working electrode was carried out by dropping on the surface $10 \mu \mathrm{L}$ of suspension of carboxylic acid-functionalized MWCNT $\left(5 \mathrm{mg} \mathrm{mL}^{-1}\right)$ and PAH $\left(3 \mathrm{mg} \mathrm{mL}^{-1}\right)$ in DMF, and evaporating during $24 \mathrm{~h}$ at room temperature. Covalent immobilization of antibodies on MWCNT-PAH/SPE was carried out by dropping $10 \mu \mathrm{L}$ of $2 \%$ glutaraldehyde, followed by $30 \mu \mathrm{L}$ of antibody mixtures ( $5 \mu \mathrm{g} \mathrm{mL}^{-1}$ antibody of each bacterium) in $0.1 \mathrm{M}$ carbonate buffer of $\mathrm{pH} 8.5$ on the electrode surface and drying at room temperature for $3 \mathrm{~h}$ and washed with $0.1 \mathrm{M}$ carbonate buffer. Unreacted aldehyde groups were blocked by $0.01 \mathrm{M}$ ethanolamine and nonspecific bindings were also blocked by $0.1 \%$ BSA containing Tris- $\mathrm{HCl}$ buffer.

\subsection{Assay procedure}

The antibody immobilized MWCNT-PAH/SPE was incubated for 30 min with $100 \mu \mathrm{L}$ of the standard bacterial cells spiked milk sample in Tris- $\mathrm{HCl}$ buffer followed by washing with Tris- $\mathrm{HCl}$ buffer. Next, MWCNT-PAH/SPE was incubated for $30 \mathrm{~min}$ with $25 \mu \mathrm{L}$ of NC bioconjugates in a $100 \mu \mathrm{L}$ of Tris- $\mathrm{HCl}$ buffer. SPE was washed again with $100 \mu \mathrm{L}$ of Tris- $\mathrm{HCl}$ buffer. Dissolution of the bound $\mathrm{NC}$ was carried out by the addition of $\mathrm{HNO}_{3}(20 \mu \mathrm{L}, 0.1 \mathrm{M})$ and followed by addition of $30 \mu \mathrm{L}$ of acetate buffer $(0.1 \mathrm{M}, \mathrm{pH} 4.6)$ spiked with 10 ppm mercury (II) nitrate for enhancing metal deposition and stripping performances. The electrochemical stripping 

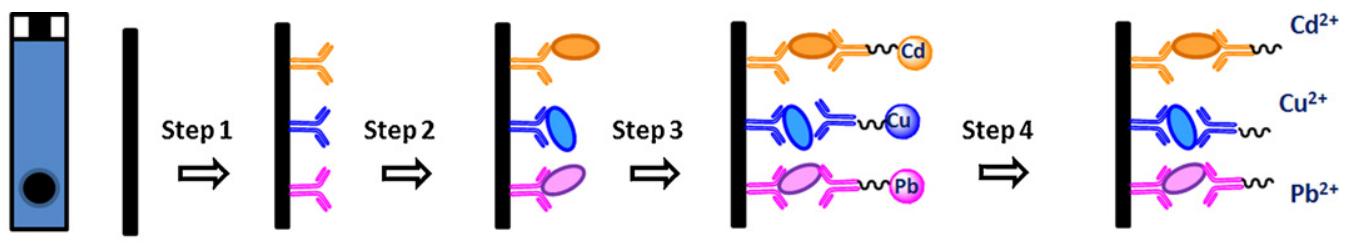

-E-Coli, -Salmonella; -Campylobacter;

$\Rightarrow$ Monoclonal antibodies of bacteria

CdS nanocrystal tagged anti E-Coli antibody

CuS nanocrystal tagged anti Salmonella antibody

PbS nanocrystal tagged anti Campylobacter antibody
\Step 5

Anodic stripping voltammetery

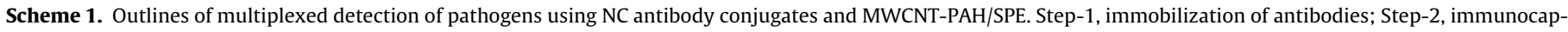
ture; Step-3, NC-antibody conjugates immunobinding; Step-4, dissolution of metal ions from NC; Step-5, SWSV analysis.

detection involved a 1 min pretreatment at $+0.6 \mathrm{~V}$, and 2 min electrodeposition at $-1.0 \mathrm{~V}$, and stripping from $-1.0 \mathrm{~V}$ to $0.0 \mathrm{~V}$ using a square-wave voltammetric waveform, with $4 \mathrm{mV}$ potential steps, $25 \mathrm{~Hz}$ frequency and $50 \mathrm{mV}$ amplitude.

\subsection{Milk sample analysis}

Commercial grade fresh bovine milk (Four ways, Taiwan) samples were clarified by centrifugation and filtration through a $0.4 \mu \mathrm{m}$ filter prior to the analysis. All milk samples were stored in $-20^{\circ} \mathrm{C}$. Samples of the milk were spiked with different combination of bacteria such as E. coli, Campylobacter and Salmonella and immediately tested.

\section{Results and discussion}

Scheme 1 depicts the outlines of an analytical technique that we developed for the amplified detection of the pathogens. The surface-modified-electrode-fabrication technology is commonly used to increase the electrode performance over the analytes. Carbon nanotubes do not disperse easily in liquids or polymer matrices. The extended $\pi$-electron system present in the tube walls leads to attractive van der Waals forces that are enhanced by the fact that tubes can interact over extended distances. The resulting side-by-side aggregates of CNTs, so called "ropes" [29], are very difficult to disrupt. Hence MWCNTs were functionalized with carboxylic group to get better dispersion. The FTIR studies of carboxylic acid-functionalized MWCNT indicates broad absorption peak at $3430 \mathrm{~cm}^{-1}$ for the $\mathrm{OH}$ functionality. A small peak at $1710 \mathrm{~cm}^{-1}$ is associated with the $\mathrm{C}=\mathrm{O}$ stretching of the carboxylic acid $(-\mathrm{COOH})$ group. The peak at $1600 \mathrm{~cm}^{-1}$ is due to $\mathrm{C}=\mathrm{C}$ stretching of the CNTs. The peak at $1380 \mathrm{~cm}^{-1}$ is due to $\mathrm{O}-\mathrm{H}$ bending deformation in $-\mathrm{COOH}$. Thus the generation of $-\mathrm{OH}$ and $-\mathrm{COOH}$ groups on MWCNTs due to functionalization was observed (Supporting information Fig. S1) [30]. In order to prevent the MWCNT from aggregating into clumps, they were enclosed in a partially polyallylamine matrix. A polyallylamine monolayer was built on the surface of carboxylic acid-functionalized MWCNT with negatively charged COO- based on electrostatic interaction. The positively charged cationic polyelectrolytes act as glue, bridging between neighbouring tubes. The $-\mathrm{NH}_{2}$ group present in the polymer chains is used for antibody immobilization. The surface morphology of the modified SPE is an important factor affecting the immunosensor performance. Fig. 1 shows the morphologies of MWCNT-PAH/SPE by scanning electron microscope. The surface of modified SPE showed a homogenous porous structure with a uniform distribution resulting from the thin film of MWCNT-PAH nanocomposite on SPE. The performance of new MWCNT-PAH/SPE was demonstrated in connection with the detection of free cadmium ion in solution. Fig. 2 compares the SWASV responses of SPE and MWCNT-PAH/SPE. Both electrodes give three well-defined oxidation peaks around at $-0.7 \mathrm{~V}$ for $\mathrm{Cd}^{2+},-0.5 \mathrm{~V}$ for $\mathrm{Pb}^{2+}$ and $-0.1 \mathrm{~V}$ for $\mathrm{Cu}^{2+}$ in acetate buffer with $10 \mathrm{ppm} \mathrm{Hg}^{2+}$. As expected, MWCNT-PAH/SPE behavior

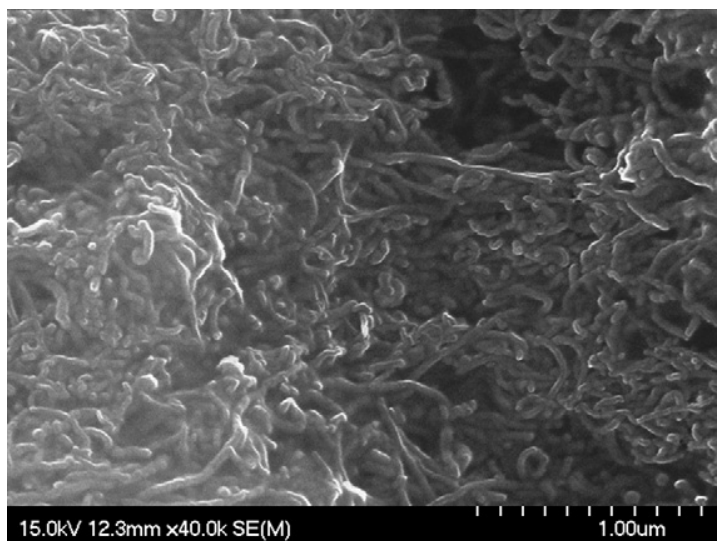

Fig. 1. SEM image of MWCNT-PAH/SPE surface structure.

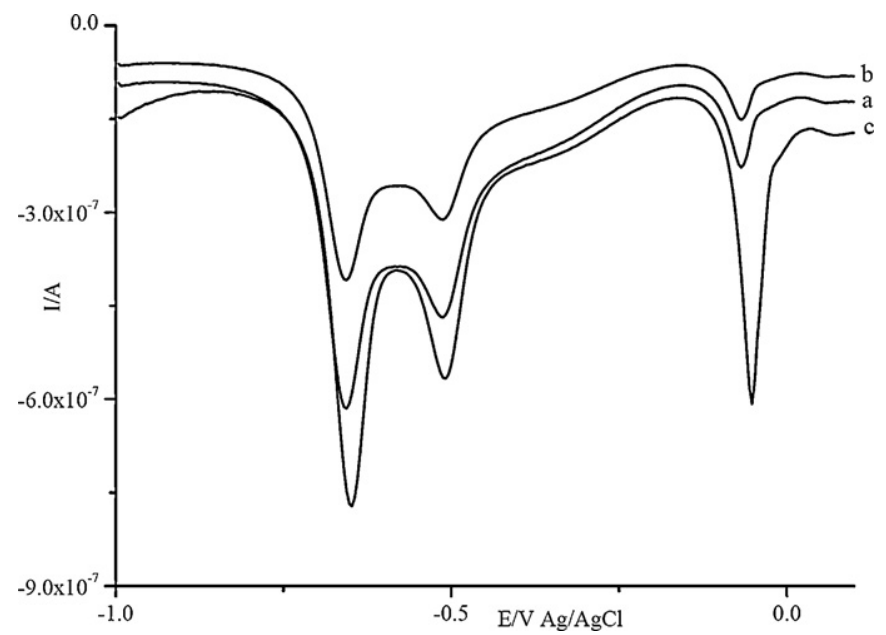

Fig. 2. Comparison of electrode performance using SWASV responses of $100 \mathrm{ppb}$ of $\mathrm{Cu}^{2+}, \mathrm{Pb}^{2+}$ and $\mathrm{Cd}^{2+}$ ions at (a) SPE, (b) PAH/SPE, and (c) MWCNT-PAH/SPE. 


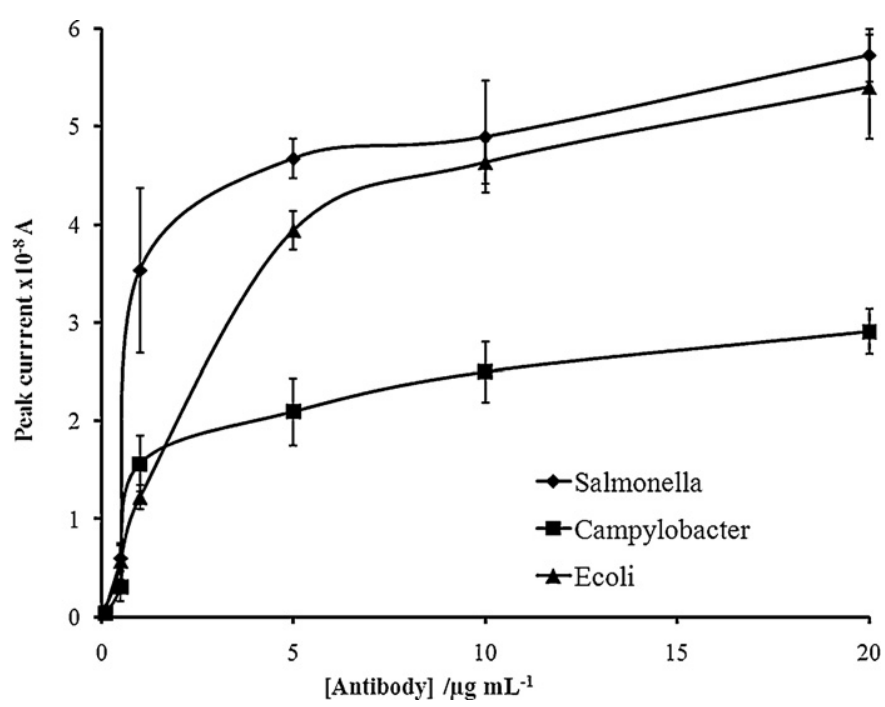

Fig. 3. Effect of antibodies concentration on antibodies immobilization process at MWCNT-PAH/SPE surface.

exhibits a more-favorable response when using voltammetric analysis then SPE or SPE modified only with PAH. MWCNT-PAH/SPE films enhanced the peak currents due to their particular electrical properties.

All three antibodies were immobilized on the MWCNT-PAH/SPE using glutaraldehyde as a cross linking agent. It is apparent that the conventional polymer protein immobilization usually settled in bulk thus creates steric hindrance to the assessment of either antigen or antibody to the entrapped counter immunological moiety. But the covalent immobilization of antibodies on MWCNT-PAH/SPE surface can only occurred on top layers. Hence this method offered no loss of biological activity and amount of antibodies at washing steps. Higher surface area of carbon nanotube modified electrode provides more accommodation for antibodies on the electrode. High selectivity was achieved by blocking the nonspecific binding of the immunosensor with $0.2 \mathrm{M}$ ethanolamine and $0.1 \% \mathrm{BSA}$ solution.

This immunoassay involved with binding event between NC conjugated antibodies and antibody sensitized electrode surface with respect to concentration of bacteria. The method chosen for detecting the dissolved NC tracers is square-wave anodic stripping voltammetry (SWASV) as it combines the amplification feature of the stripping technique with the advantage of squarewave voltammetry. The coupling of sensitive MWCNT-PAH/SPE and NC-antibody conjugates based stripping assays showed good performance. In these cases, different concentrations of antibodies were immobilized onto the polymer matrix. It is clear from Fig. 3 that the sensor response increased significantly when the concentration of antibody loaded on the electrode surface was changed from 0.01 to $5 \mu \mathrm{g} \mathrm{mL}^{-1}$. With further increase in the antibody concentration to $5-20 \mu \mathrm{g} \mathrm{mL}^{-1}$, the significant increases of

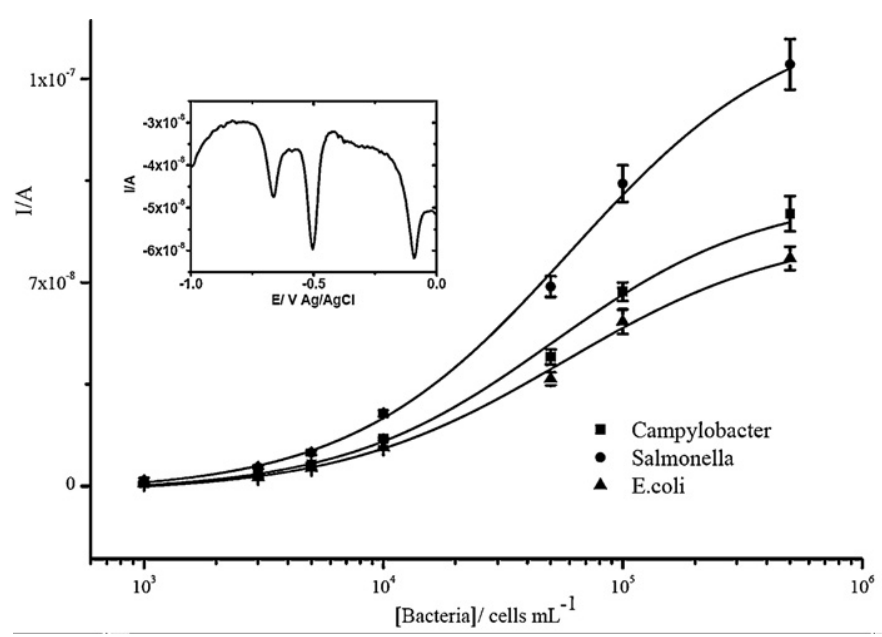

Fig. 4. Calibration curve for three selected bacteria under optimized conditions Inset: SWASV response for $10^{4}$ cells $\mathrm{mL}^{-1}$ of E. coli, Salmonella and Campylobacter pathogens.

the sensor response was not observed. Hence $5 \mu \mathrm{g} \mathrm{mL}{ }^{-1}$ was taken as optimum. The antibodies immobilized electrode was allowed to incubate with $100 \mu \mathrm{L}$ solution of bacteria mixtures for different periods of time. The results show that the SWASV signal increased rapidly with the incubation time up to $30 \mathrm{~min}$, and then the electrode did not show any significant increases in signal as incubation time increased. Thus $30 \mathrm{~min}$ was selected as the optimum. Immuno-captured bacteria on the electrode was incubated with NC-antibody conjugates for $30 \mathrm{~min}$ and followed by voltammetric studies. The amount of bound NC on the electrode surface is directly proportional to the bacteria concentration present in corresponding samples. An inset Fig. 4 displays typical SWASV for solutions containing $1 \times 10^{4}$ cells $\mathrm{mL}^{-1}$ of bacteria. A mixture of three antibody-conjugated nanocrystals yielded sharp and baseline-resolved peaks around at $-0.7 \mathrm{~V}$ (E. coli), $-0.5 \mathrm{~V}$ (Campylobacter) and $-0.1 \mathrm{~V}$ (Salmonella). The peak current was proportional to the target concentration. In contrast, no response is observed for the corresponding control experiment without the bacteria reflecting the absence of nonspecific adsorption on immunosensor.

\subsection{Analytical calibration}

The analytical calibrations for bacteria were conducted to determine the sensitivity of the immunosensor towards bacteria, and the immunosensors were tested with different concentrations of the target analyte. The calibration curve for the voltammetric detection of bacteria was carried out by recording each concentration of mixture of bacteria, the response of a modified electrode at optimum experimental conditions (Fig. 4). Each point of the calibration graph corresponds to the mean value obtained from 5 independent measurements. A sigmoidal current variation was observed

Table 1

Recovery studies of selected bacteria from spiked bovine milk samples using NC antibody conjugates and immunosensitized MWCNT-PAH/SPE.

\begin{tabular}{|c|c|c|c|c|c|c|}
\hline \multirow[t]{2}{*}{ S. no } & \multicolumn{3}{|c|}{ Amount of bacteria spiked $/ \mathrm{mL}$} & \multicolumn{3}{|c|}{ Percentage of recovery $(n=3)$} \\
\hline & E. coli & Campylobacter & Salmonella & E. coli & Campylobacter & Salmonella \\
\hline 1 & $1 \times 10^{4}$ & - & - & $91 \pm 7$ & - & - \\
\hline 2 & - & $1 \times 10^{4}$ & - & - & $88 \pm 6$ & - \\
\hline 3 & - & - & $1 \times 10^{4}$ & - & - & $101 \pm 6$ \\
\hline 4 & $1 \times 10^{4}$ & $1 \times 10^{4}$ & - & $90 \pm 5$ & $86 \pm 4$ & - \\
\hline 5 & $1 \times 10^{4}$ & - & $1 \times 10^{4}$ & $87 \pm 5$ & - & $93 \pm 5$ \\
\hline 6 & - & $1 \times 10^{4}$ & $1 \times 10^{4}$ & - & $86 \pm 6$ & $95 \pm 4$ \\
\hline 7 & $1 \times 10^{4}$ & $1 \times 10^{4}$ & $1 \times 10^{4}$ & $89 \pm 6$ & $103 \pm 5$ & $89 \pm 5$ \\
\hline
\end{tabular}


over the range of $1 \times 10^{3}-5 \times 10^{5}$ cells $\mathrm{mL}^{-1}$. The limit of detection (LOD) was defined as the lowest amount of bacterial cells producing a peak current 3 times higher than the standard deviation of the background current in the absence of bacteria under identical conditions. The LOD values of Salmonella, Campylobacter and E. coli were found to be 400,400 and 800 cells $\mathrm{mL}^{-1}$ respectively, with coefficient variation below 7\%. It indicated that the immunosensor response and fabrication procedure were reproducible. Recently reported methods for the detection of selected pathogens are summarized in Table S1. The present electrochemical biosensors for the multiplexed detection of pathogens with low detection limit shows better than previous reports.

\subsection{Spiked milk sample analysis}

Different combinations of bacteria were spiked and tested for recovery analysis. In Table 1, the analysis results of the spiked milk sample tested with this developed immunosensor are reported. These results revealed that this immunosensor is capable of multiplexed detection of pathogenic bacteria present in milk.

\section{Conclusion}

In this study, we have developed a highly amplified, nanocrystal-based, bio-barcoded electrochemical immunosensor for the simultaneous multiplexed detection of the food pathogens. An electrochemical immunosensor was prepared by immobilization of antibodies on MWCNT-PAH/SPE. The biosensor is mainly composed of three different nanocrystal tracers, such as CuS, PbS and CdS. After the nanocrystal tracer is dissolved in $0.1 \mathrm{M}$ nitric acid, the metal ions, such as $\mathrm{Cu}^{2+}, \mathrm{Pb}^{2+}$ and $\mathrm{Cd}^{2+}$, show distinct nonoverlapping stripping curves by SWASV on SPE. The integration of the nanocrystal and antibody meets the demand of facilitating the electrochemical immunoassay detection levels. The multiwall carbon nanotubes improve the performance of the electrochemical reaction of substrate and increase the sensitivity of the multiplexed detection of bacteria. The nanocrystal-based bio-barcoded pathogen sensor has potential applications for multiple detections of bioterrorism threat agents and food contaminants. Our results suggest that the assay can be directly applied for food quality control applications, although a larger scale laboratory validation study with a greater number of samples will be required to determine the diagnostic sensitivity and specificity.

\section{Appendix A. Supplementary data}

Supplementary data associated with this article can be found, in the online version, at doi:10.1016/j.talanta.2012.03.049.

\section{References}

[1] E. Tuomanen, Science 308 (2005), 635-635

[2] V. Velusamy, K. Arshak, O. Korostynska, K. Oliwa, C. Adley, Biotechnol. Adv. 28 (2010) 232-254.

[3] R.L. Caygill, G.E. Blair, P.A. Millner, Anal. Chim. Acta 681 (2010) 8-15

[4] A.K. Bhunia, Food Technol. 65 (2011) 38-43.

[5] P. Leonard, S. Hearty, J. Brennan, L. Dunne, J. Quinn, T. Chakraborty, R. O’Kennedy, Enzyme Microb. Technol. 32 (2003) 3-13.

[6] D.A. Powell, C.J. Jacob, B.J. Chapman, Food Control 22 (2011) 817-822.

[7] S. van der Veen, T. Abee, Curr. Opin. Biotechnol. 22 (2011) 136-142.

[8] C. Hedberg, Emerg. Infect. Dis. 5 (1999) 840-841.

[9] S.M. Pires, H. Vigre, P. Makela, T. Hald, Foodborne Pathog. Dis. 7 (2010) 1351-1361.

[10] T.F. Jones, L.A. Ingram, P.R. Cieslak, D.J. Vugia, M. Tobin-D’Angelo, S. Hurd, C. Medus, A. Cronquist, F.J. Angulo, J. Infect. Dis. 198 (2008) 109-114.

[11] A.G. Plaut, J. Food Prot. 63 (2000) 822-826.

[12] E.C.D. Todd, World Health Stat. Q 50 (1997) 30-50.

[13] M.N. Swartz, Clin. Infect. Dis. 34 (2002) S111-S122.

[14] C. Christy, Pediatr. Infect. Dis. J. 18 (1999) 911-912.

[15] O.L. Henao, E. Scallan, B. Mahon, R.M. Hoekstra, Foodborne Pathog. Dis. 7 (2010) 1421-1426.

[16] A. Rompre, P. Servais, J. Baudart, M.R. de-Roubin, P. Laurent, J. Microbiol. Methods 49 (2002) 31-54.

[17] M. Pedrero, S. Campuzano, J.M. Pingarron, Sensors 9 (2009) 5503-5520.

[18] C. Situ, J. Buijs, M.H. Mooney, C.T. Elliott, TrAC Trends Anal. Chem. 29 (2010) 1305-1315.

[19] M. Severgnini, P. Cremonesi, C. Consolandi, G. De Bellis, B. Castiglioni, Food Bioprocess Technol. 4 (2011) 936-953.

[20] G.A. Zelada-Guillen, S.V. Bhosale, J. Riu, F.X. Rius, Anal. Chem. 82 (2010) 9254-9260.

[21] Q. Gao, Y. Guo, W. Zhang, H. Qi, C. Zhang, Sens. Actuators B: Chem. 153 (2011) 219-225.

[22] S.N. Tan, L. Ge, W. Wang, Anal. Chem. 82 (2010) 8844-8847.

[23] T.S. Mann, S.R. Mikkelsen, Anal. Chem. 80 (2008) 843-848.

[24] H. Lian, W. Qian, L. Estevez, H. Liu, Y. Liu, T. Jiang, K. Wang, W. Guo, E.P. Giannelis, Sens. Actuators B: Chem. 156 (2011) 187-193.

[25] S. Viswanathan, L.-c. Wu, M.-R. Huang, J.-a.A. Ho, Anal. Chem. 78 (2006) 1115-1121.

[26] J.A. Hansen, J. Wang, A.-N. Kawde, Y. Xiang, K.V. Gothelf, G. Collins, J. Am. Chem. Soc. 128 (2006) 2228-2229.

[27] S. Pathak, S.-K. Choi, N. Arnheim, M.E. Thompson, J. Am. Chem. Soc. 123 (2001) 4103-4104.

[28] C.-H. Tseng, C.-C. Wang, C.-Y. Chen, Chem. Mater. 19 (2006) 308-315.

[29] J.M. Cowley, Ultramicroscopy 87 (2001) 1-4.

[30] S. Viswanathan, C. Rani, A. Vijay Anand, J.-a.A. Ho, Biosens. Bioelectron. 24 (2009) 1984-1989. 